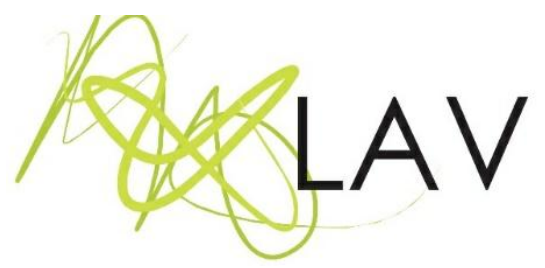

\title{
Animação, infância e fabulação: movimentos com o conceito devir-criança e produção de arte no ensino remoto
}

Animation, childhood and fabulation: movements with the concept of becoming-child and art production in remote education

Ana Cláudia Barin Rede Marista - Santa Maria/RS

\section{Resumo}

Este artigo tem como objetivo apresentar percepções sobre uma experimentação com crianças dos Anos Iniciais do Ensino Fundamental de uma escola privada e a produção em arte no ensino remoto. A proposta explorou, como disparador inicial, a animação 'Viva - A Vida é uma Festa', a produção de fotografias e os conceitos de devir-criança a partir de autores como Gilles Deleuze e Félix Guattari $(2010,2012)$ e infância, a partir de Walter Kohan (2007) e César Leite (2011). O percurso metodológico desenhado para esta experimentação foi a fabulação, termo que advém do conceito de Ronald Bogue (2011), que pensa movimentos inusitados com a invenção para a produção de conhecimento. Nos resultados dessa experimentação foi possível observar as relações com a infância e o devircriança e, constatar que a invenção vai se elaborando nas possibilidades de criação com o que se tem, entre respiros e fissuras.

Palavras-chave: Devir-criança, Infância, Fabulação, Educação, Arte.

\begin{abstract}
The present article aims at presenting perceptions about an experimentation with children from the Early Years of Elementary School in a private school and the production of art in remote education. The proposal explored the 'Live - Life is a Party' animation, the production of photographs and the concepts of becoming-child from authors such as Gilles Deleuze and Félix Guattari $(2010,2012)$ and childhood, from Walter Kohan (2007) and César Leite (2011). The methodological path designed for this experimentation was the fable, a term that comes from the concept of Ronald Bogue (2011), who thinks of unusual movements with the invention for the production of knowledge. In the results of this experimentation, it was possible to observe the relationships with childhood and the becoming-child and, to verify that the invention is elaborated in the possibilities of creation with what one has, between breaths and fissures.
\end{abstract}

Keywords: Child-becoming, Childhood, Fabulation, Education, Art. 


\section{Introdução}

Esta escrita apresenta percepções sobre uma proposta realizada com crianças dos Anos Iniciais do Ensino Fundamental de uma escola particular a partir do ensino remoto de 2020. A experimentação explorou o filme ganhador do Oscar de melhor animação no ano de 2018, 'Viva - A Vida é uma Festa' e os conceitos de infância e devir-criança a partir dos autores como Gilles Deleuze, Félix Guattari (2010, 2012) Walter Kohan (2007) e César Leite (2011). A proposta foi lançada com o propósito de pensar estratégias em meio a ações das aulas remotas, na qual os movimentos de desencaixes foram necessários para que a atividade pudesse ser realizada, adentrando no escopo da produção de conhecimento em artes.

$\mathrm{Na}$ busca por respiros e brechas nas atividades educativas encaminhadas aos estudantes, muitas vezes nos perguntamos com que elementos devemos elaborar tais questionamentos, quando na verdade poderíamos nos movimentar em como construir coletivamente experiências significativas para as crianças. Foi desta forma que utilizei como objeto potencializador para a proposta em questão a animação 'Viva - A Vida é uma Festa', juntamente com os conceitos de infância e devir-criança. Primeiramente, foi lançado um convite para que as crianças pudessem assistir ao filme junto com seus familiares, construindo assim relações de questionamentos compartilhados nos instantes da animação. Ao assistirem ao filme e mergulharem na fantástica história do personagem principal Miguel Rivera, a solicitação da atividade era produzir uma fotografia, que poderia ser construída de maneira individual ou coletiva, com a família, retratando a estética singular que o filme expõe.

Movimentado durante toda a animação pela curiosidade, Miguel Rivera é um menino de 12 anos que vai atrás de respostas sobre rituais tradicionais da sua família que envolve a famoso feriado do "Dia dos Mortos", no México, onde se fazem oferendas aos falecidos com uma grandiosa festa e muitos adornos coloridos. Percebemos no personagem uma inquietante busca que não cessa em somente ouvir as explicações dadas a ele pela família, e assim é impulsionado pelo desejo de descobrir o que ele ainda não sabe. Esta é a potência que abraça o personagem Miguel durante toda a animação, atravessada por uma vontade de aventurar-se pelo desconhecido e adentrar nas possibilidades de estar se (re) inventando a cada passo, a cada salto, a cada descoberta.

O conceito devir-criança deriva de produzir agenciamentos, potencializar as intensidades, encontros com o inusitado, com o novo, o inédito e, possivelmente, com a invenção. Foi assim que Miguel movimentou-se, em meio a sua aventura por descobertas múltiplas e deslumbrantes. É importante pontuar que o devir-criança não é próprio e exclusivo das crianças, nem tão pouco uma imitação do estado infantil. Não é imitar um 
cão ao latir, mas compor seu corpo com partículas que serão caninas em função do movimento e do repouso (DELEUZE; GUATTARI, 2012). Não trata-se, portanto, em momento algum de agir como uma criança ou infantilizar-se. O devir-criança, como conceito, não pode ser acionado, uma vez que ele nos aciona, somos abarrotados por ele, por um cheiro que nos enlaça, por um encontro, uma imagem, um afeto, um filme, uma animação.

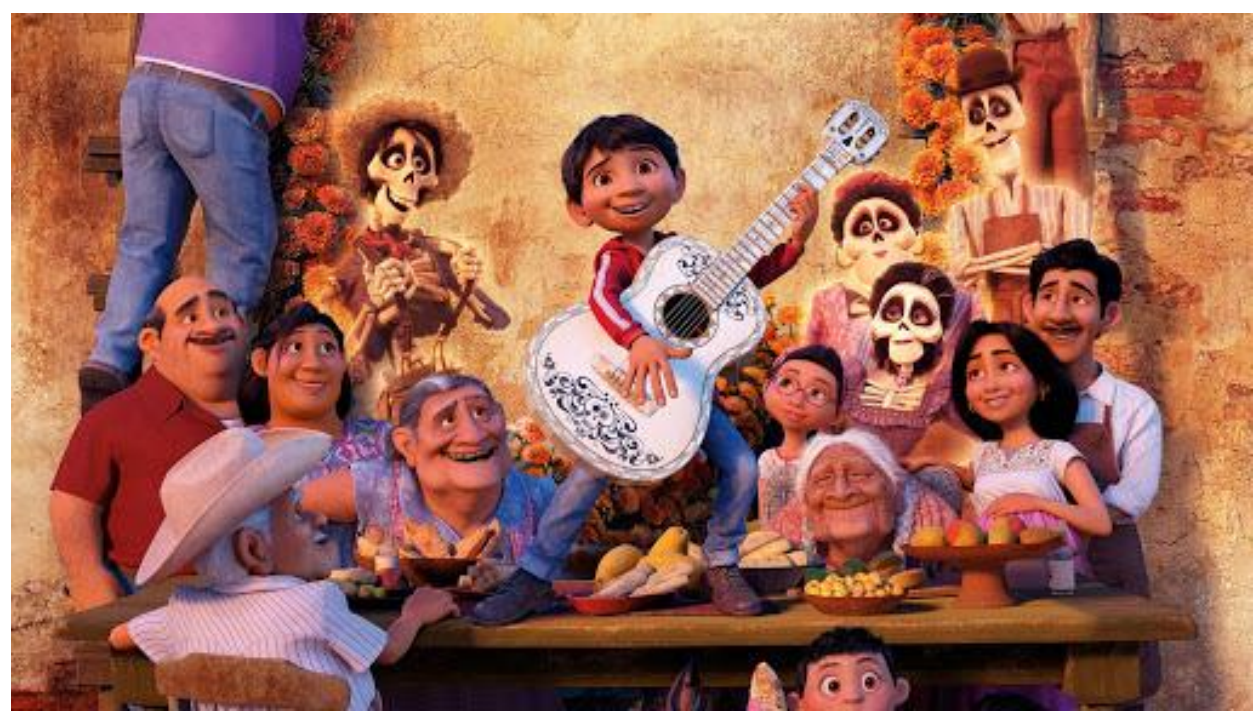

Figura 1: Recorte da Animação 'Viva - A Vida é uma Festa' (2018)

Fonte: http://www.aplateia.com.br/2020/08/25/viva-a-vida-e-uma-festa-e-o-amor-emfamilia/ (2020).

Instigou-se, com estes desencaixes, a experimentação com as fotografias e como cada estudante lidou com suas próprias produções inventivas a partir de suas escolhas. Ficou a critério das crianças a elaboração das imagens fotográficas, a construção do cenário e das roupas e o convite para a participação de um membro da família. O desafio de colocar a proposta no coletivo desacomodou os agentes de formação educativa e a responsabilidade que recaída normalmente somente aos professores quando se trata do 'ato de ensinar'.

Em tempos de crise e isolamento, foi necessário um trabalho em conjunto com as famílias para que certos movimentos fossem possíveis no campo da educação, pensando na ação do ensino remoto. Mais ainda, quando nos dispomos a elaborar as experimentações com as artes. Segundo Deleuze e Guattari (2010, p. 133) "pensar é experimentar, mas a experimentação é sempre o que se está fazendo - o novo, o notável, o interessante". A intenção da experimentação com as fotografias a partir da animação 'Viva - A Vida é uma Festa' foi fazer brotar das fissuras a invenção, o que ainda não tinha sido pensado, mas que estava prestes a ser criado. 
Assim como o autor César Leite (2011) questiona, insistentemente, sobre a infância: seria esta possível de se antecipar? Quando oportunizamos aberturas para que a infância vaze, pense o ainda impensável, o que ainda não foi visto, escrito ou produzido, expandimos uma noção de infância outra(s), infância potência, que permite que as propostas educativas não se limitem as fronteiras reduzidas do que o ensino remoto apresenta como ferramenta, ou seja, uma simples tela de computador. Podemos pensar na "possibilidade de criar modos de dizer sobre a infância" (LEITE, 2011, p. 24) quando estamos atentos ao que as crianças falam, sussurram ou cantam em seus momentos de criação.

\section{Possibilidades de caminhos metodológicos}

A ideia dos caminhos metodológicos foi pensar em uma (des)estrutura múltipla e aberta, que pudesse potencializar ao máximo a invenção dessas experimentações com as fotografias. Assim, a escolha para o método de produção desta proposta com a animação 'Viva - A Vida é uma Festa' e a construção desta escrita foi a fabulação, metodologia que ainda está sendo experimentada em algumas pesquisas que envolvem a potência do inusitado, do novo e movimentos de invenção.

A fabulação foi pensada pelo campo da arte, como a literatura e o cinema, por Gilles Deleuze e Félix Guattari e não foi tratada como conceito por estes dois autores justamente pelos conceitos estarem ligados ao campo da filosofia. Já para o autor Ronald Bogue (2011), a fabulação foi explorada como conceito. Segundo ele, a fabulação pode ser dividida em cinco componentes: devir-outro, experimentação do real, 'mito', invenção de um povo por vir e desterritorialização da linguagem. A noção de devir-outro é explorado nos livros Mil Platôs vol. 1 (2011) e vol. 4 (2012), nos quais Deleuze e Guattari o ramificam como devir-mulher, devir-animal, devir-imperceptível, devir-criança.

Todos esses devires são de natureza política, rebatendo relações de poder como das categorias de homem, branco, europeu, adulto e humano em relação ao feminino, ao não-branco, ao não europeu, à criança e ao animal. O devir-outro, segundo Bogue (2011, p. 21), "envolve uma passagem entre categorias, entre formas de existência e entre corpos distintos, de modo que elementos estáveis sejam colocados em desequilíbrio metamórfico". Assim, explorar a fabulação enquanto método, possibilitou pensar nesta proposta com as crianças ramificações de devires, nessa mobilidade cultural e no campo da educação e arte.

Uma narrativa de fabulação está centrada em modelos diferenciados, por isso não segue os mesmos princípios de uma fábula, por exemplo. O pensamento deleuziano é antinarrativo, 
rompe com a sequência temporal dos acontecimentos, não segue uma sequência cronológica. A essência da fabulação é o devir-outro, e 'devir', de acordo com Deleuze e Guattari, tem relação com a temporalidade que não é a do senso comum (BOGUE, 2011, p. 26).

Pensar fragmentos de tempo, em meio ao exercício de uma atividade artística, abriu possibilidades para que cada criança pudesse escolher o momento de começar sua proposta e sua produção com a fotografia, já que esta tinha a intenção de ser realizada em casa, espaço que se tornou pedagógico diante dos tempos que estamos vivendo, com o ensino remoto. Os desencaixes da produção do trabalho tinham como mote a animação 'Viva - A Vida é uma Festa' e a história de vida do personagem Miguel ao vivenciar uma aventura em um mundo outro, cheio de fantasias. Dessa maneira, permitiu-se que as crianças adentrassem em um percurso fabuloso, inventivo, que o filme nos mostra, construindo agenciamentos de produção coletiva, na qual as fronteiras da criação costuraram-se com as experiências de vida de cada uma dessas crianças.

A fabulação não está centrada em projetar modelos individuais e, certamente, não irá proferir sobre um povo dominador, aquele chamado para dominar o mundo: povo que segue padrões fixos ou pré-existentes, ou que se focam em paradigmas imutáveis, que servem como exemplo de padrões permanentes. Podemos dizer que o povo que está fora dessas normativas se torna gigante pela força da mediocridade (DELEUZE; GUATTARI, 2010), por sua potência de existir em invenção, por inovar-se continuamente. "Toda fabulação é fabricação de gigantes. Medíocres ou grandiosos, são demasiadamente vivos para serem vivíveis ou vividos" (DELEUZE; GUATTARI, 2010, p. 203). Movimentar uma metodologia pela fabulação é produzir-se com o que se tem, abrindo fissuras no já existente modo de pensar, para construir outros ainda mais potentes, ainda mais inventivos, ainda mais inesperados.

\section{Retratos de invenções}

Trabalhar com uma proposta que não se fechou em materiais, nem enunciados possibilitou movimentos de criação potente, tanto para as turmas, que realizaram a tarefa, quanto para mim, como docente em ação, ao observar o processo de invenção das crianças. Quando nos propomos a construir planejamentos de aulas no âmbito de educação remota, 'à distância', foi necessário rever tempos, relações de afetos e de angústias, escolhas e possibilidades de materiais disponíveis, já que na escola a gama destes materiais de artes é infinita, devido aos espaços estruturais que as escolas privadas dispõem, como os ateliês. 
Instigar os estudantes a convidarem a família para participar desta atividade foi uma surpresa inesperada que ocorreu durante o andamento da produção das fotografias. A proposta foi lançada sem uma data fechada de realização e apresentação das imagens, dando espaço para que esta criação acontecesse no tempo da criança, e mais importante, de quem divide a casa e as tarefas com essas crianças. O fato de lançar estes questionamentos a partir do conceito de devir-criança e infância foi justamente compreender que esta produção pudesse abraçar não só os estudantes de forma individual, mas que pudesse se tornar uma elaboração coletiva, junto com a família e/ou as pessoas ao redor dessas crianças.

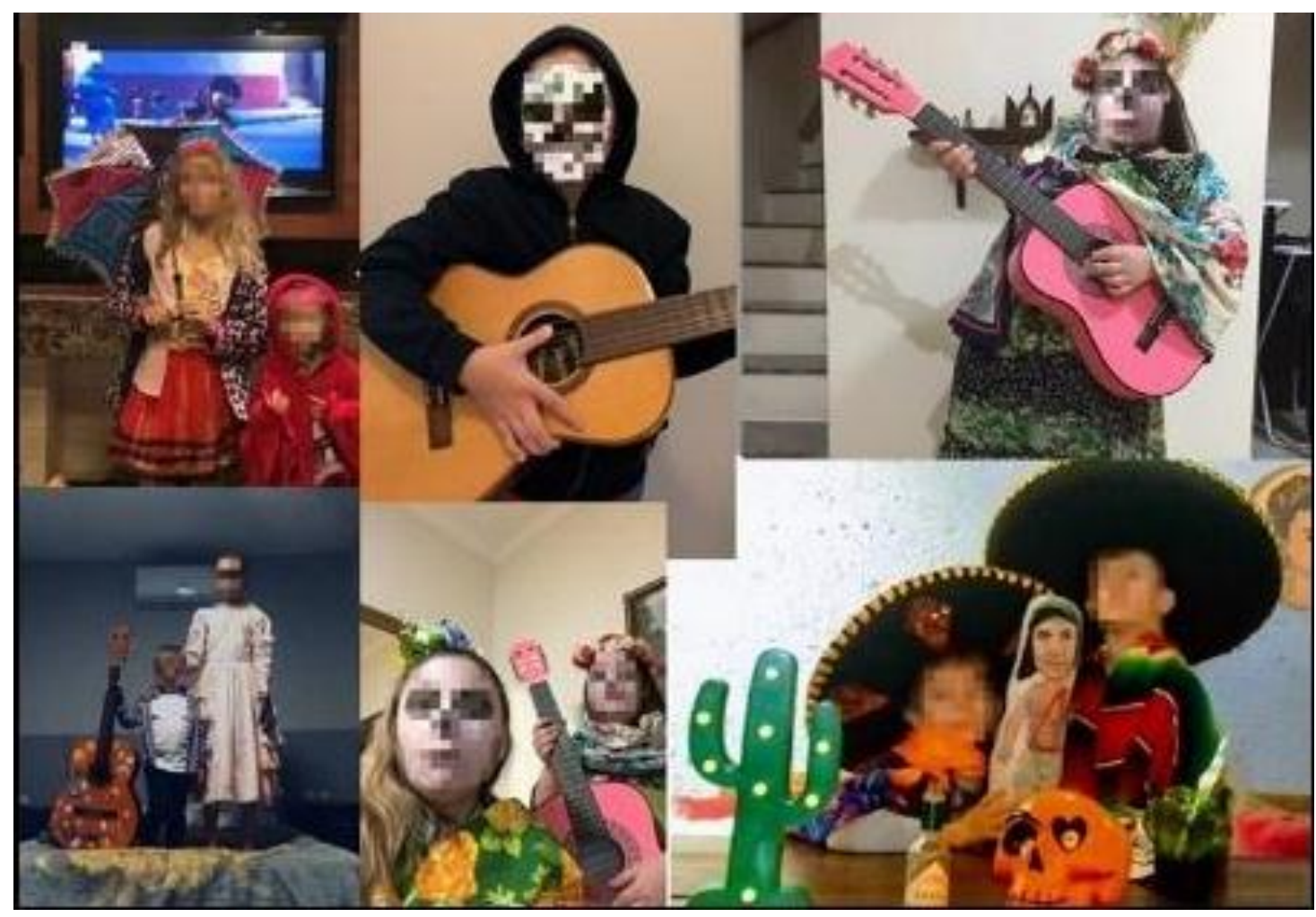

FIGURA 2: Montagem de algumas fotografias produzidas pelos estudantes a partir da proposta com a animação "Vida - A vida é uma Festa" Fonte: Arquivo pessoal (2020).

As fotos surgiram incrivelmente coloridas, com preocupações estéticas bem desenvolvidas, com elementos e objetos que tinham conexões pertinentes com a harmonia mostrada na animação 'Viva - A vida é uma Festa'. O convite para usar a foto como resultado final da atividade foi para pensar recursos além do material comum que eles estavam utilizando em casa, como folha branca e lápis de cor, tendo como produto somente os desenhos.

Entender que alguns conseguem manipular imagens, montar cenários e escolher fantasias foi compreender os movimentos importantes ao pensar uma infância como 
potência, perceber as sensações vivenciadas com a experimentação e os diferentes tempos vividos para além do filme e da vida do personagem Miguel.

As brincadeiras das crianças guardam, em si, não experiências vazias e homogêneas, mas virtualidades e heterogeneidades; fogem do tempo e indicam abertura a outra noção de tempo, que irrompem no vazio da experiência produzindo um espaço de sensações (LEITE, 2011, p. 85).

Misturar a proposta de atividades escolares com uma brincadeira fez com que as fronteiras da invenção não fossem delimitadas, ocasionando, assim, questionamentos pertinentes à educação junto ao isolamento: o que posso em uma aula? Ou mais ainda: como posso produzir muitos mundos em uma aula de artes?

Dessa forma, foram-se construindo resultados que ultrapassaram qualquer medida do que pudesse se esperar, em devir, na qual muitos ainda tiveram a ideia de produzir vídeos, curtas e frames a partir do filme, arriscando outras maneiras de atender o convite da proposta feita.

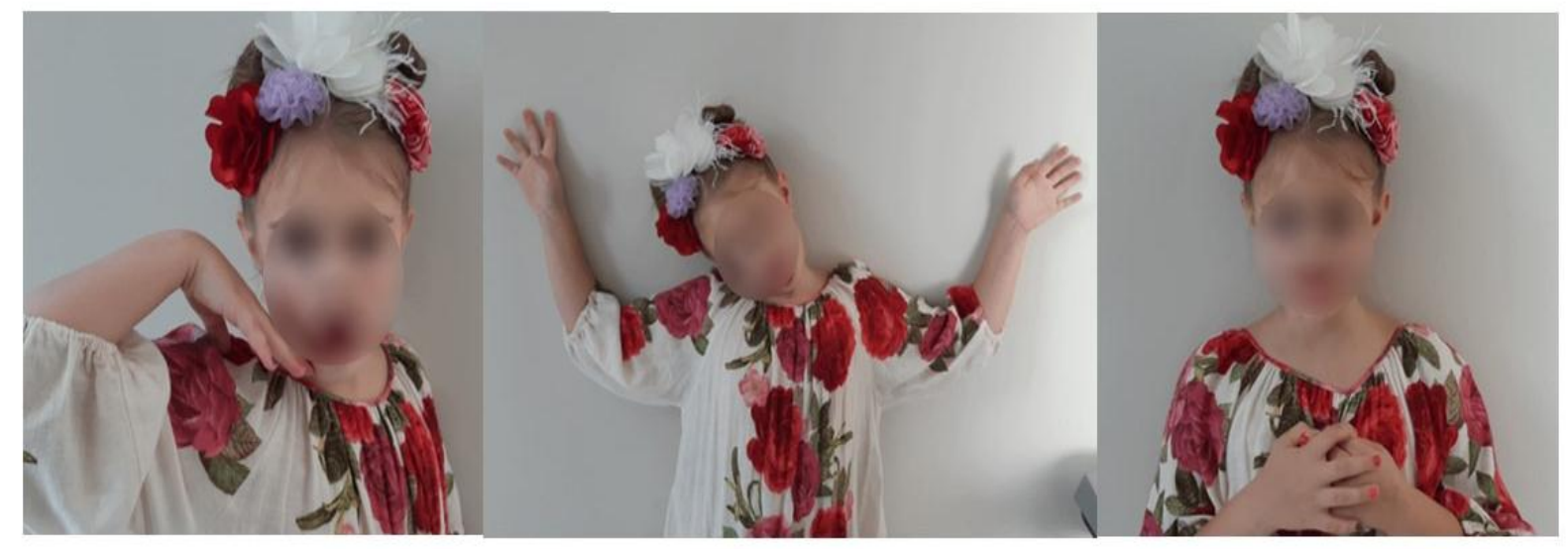

Figura 3: Fragmentos de vídeo produzido por uma estudante a partir da proposta com a animação "Vida - A vida é uma Festa"

Fonte: Arquivo pessoal (2020)

Ao pensarmos no olhar da criança, percebemos como elas enxergam o mundo que as cercam, quais experiências produzem com este mundo e como inventam e reinventam situações dentro deste(s) mundo(s). A infância pensada por este outro viés, como potência e resistência, mergulha em um mundo que pode se fabricar junto a fabulação e em devir.

O conceito de devir-criança perpassa pelo rompimento dessas segmentações e estratificações fixas, como muitas vezes a infância pode ser vista e documentada. As minorias quebram as percepções de centralidade, gotejam no sistema anárquico, são os 
negros, mulheres, crianças. Assim como pode existir em todos nós o devir-criança, este movimenta-se em diferentes fases da vida, independente da idade que temos.

"É o devir que faz, do mínimo trajeto ou mesmo de uma imobilidade no mesmo lugar, uma viagem; e é o trajeto que faz do imaginário um devir" (DELEUZE, 2011, p. 88). Podemos pensar o devir como um movimento constante de afetos, fissuras, onde um "acontecimento interrompe a história, a revolucionam, criam uma nova história, um novo início" (KOHAN, 2007, p. 92). E foi assim, em meio a trajetos inventivos, que pude perceber a construção dessas imagens a partir do filme, envolvendo um agenciamento entre afetos, encontros e imaginação. A ideia jamais era imitar ou copiar um trecho da animação, e sim construir nas brechas, nas entrelinhas uma nova narrativa, uma história outra.

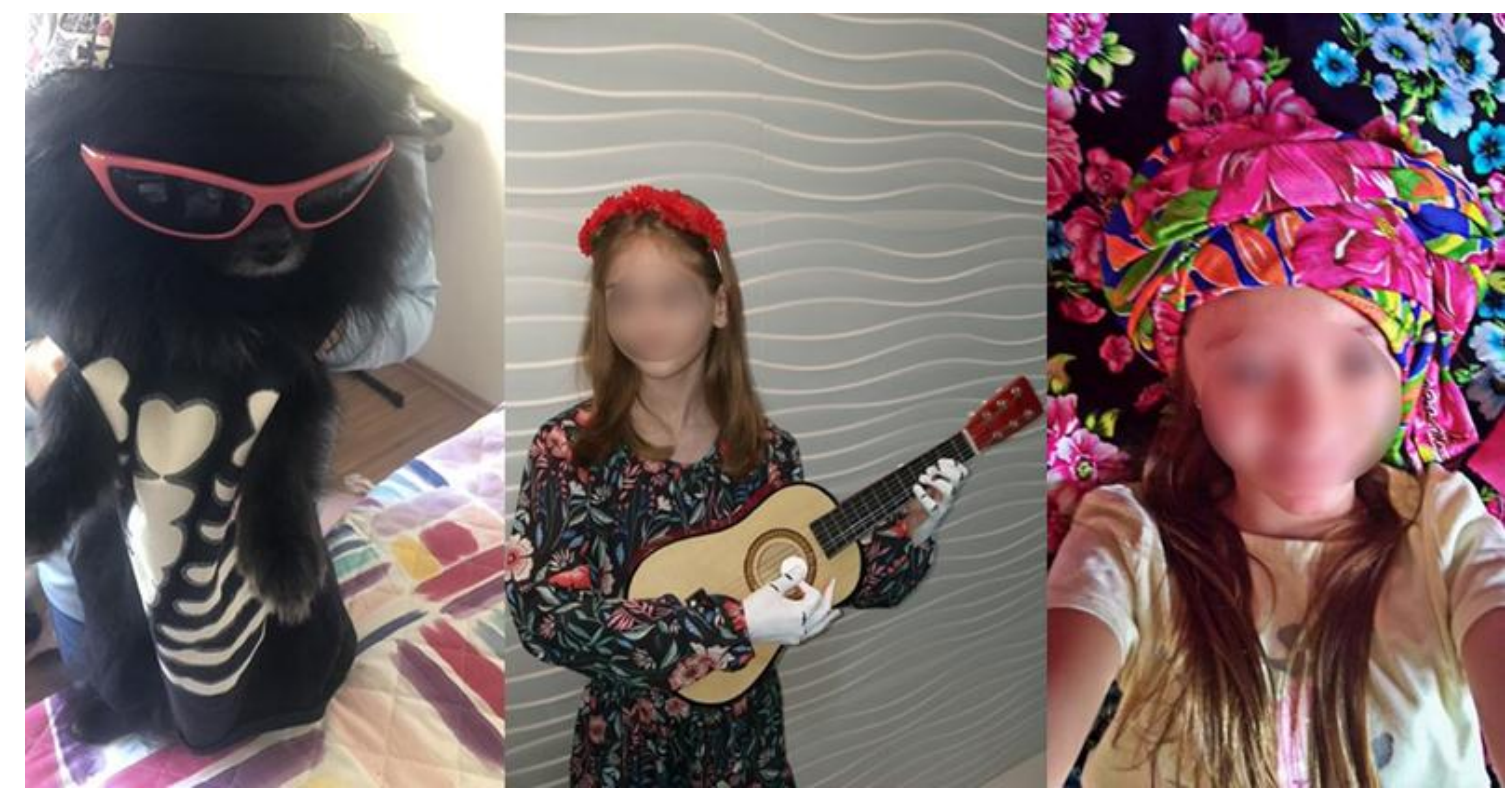

Figura 4: Montagem de algumas fotografias produzidas pelos estudantes a partir da proposta com a animação "Vida - A vida é uma Festa" Fonte: Arquivo pessoal (2020).

A intenção da experimentação com as fotografias a partir da animação foi fazer brotar das fissuras a invenção de muitos tempos, o que ainda não tinha sido pensado ou imaginado, mas que estava prestes a ser produzido, tanto individualmente, como coletivamente. Ao observar os resultados dessa experimentação que envolveu relações com o devir-criança e a infância, foi possível constatar que a invenção de constrói justamente nas possibilidades de criação com o que se tem disponível, com o coletivo e entre respiros de uma educação que caminha se adaptando, sempre em vias de engendrarse com os percursos inusitados. 


\section{Conclusões de costuras que seguem}

Quando nos deparamos com desafios tão pertinentes, como nos é apresentado aos dias atuais, com o ensino remoto e a mudança grande de percepção em relação à educação, penso que podemos nos concentrar mais nas estratégias que movimentamos com os estudantes do que nos conteúdos trabalhados em si. Foi desta maneira que construí esta proposta que envolvia animação e a produção de fotografias.

Aprender como se constitui uma educação pela fabulação, tendo em vista disparadores como estes apresentados aqui, operados pelo conceito de devir-criança que oportuniza tantos possíveis e pensar uma infância outra fez com que eu estivesse atenta aos olhares que as crianças sinalizavam, podendo assim explorar estes muitos mundos que eles nos apresentam. Conceber essas relações é justamente engendrar o pensamento a partir da criança, das ferramentas disponíveis e da arte, atualizando tempos, remontando imagens, para mergulhar em uma educação costurada pela fabulação.

Dessa forma, compreendi que os resultados desse trabalho perpassam pelas possíveis aprendizagens, mesmo em tempos de ensino remoto, na qual os limites são ultrapassados para experimentar o que ainda não foi vivenciado. A abertura da infância (LEITE, 2011) oportuniza aproximar a educação do modo de existência das crianças e da forma como elas se posicionam em relação ao mundo, a produção de conhecimento e criação de imagens. O âmbito artístico permite, aqui, impulsionar novos e instigantes desafios para lidar com a distância do ambiente da escola, da sala de aula, da troca de proximidade com os colegas e das relações de afetos que o espaço escolar permite.

Assim, fiz os movimentos em fabulação, sempre estando atenta em como as crianças apresentam suas percepções e em como ouvi-las pode oportunizar um outro olhar para nosso trabalho como docentes e nossas construções de conhecimento. Acredito muito na potência dos acontecimentos, dos enunciados em devir e que pensar mais no campo das incertezas do que das verdades absolutas pode contribuir para o campo da educação e da arte. Dessa maneira, vou construindo meus questionamentos, com a arte, com a invenção, com pesquisas que não acabam em si e que estão sempre em movimento [de seguir].

\section{Referências}

BOGUE, R. Por uma teoria deleuziana da fabulação. In: AMORIN, A. Carlos; MARQUES, Davina; DIAS, Suzana O. (Orgs.) Conexões: Deleuze e Vida e Fabulações e... - Petrópolis, RJ: De Petrus; Brasília, DF: CNPq: Campinas ALB, 2011, p. 17-35.

DELEUZE, G. Crítica e Clínica. Tradução de Peter Pál Pelbart. - São Paulo: Editora 34, 2011.

Revista Digital do LAV - Santa Maria - vol. 14, n. 2, p. 311 - 320 - mai./ago. 2021 ISSN 1983 - 7348 http://dx.doi.org/10.5902/1983734865564 
DELEUZE, G.; GUATTARI, F. O que é filosofia? Tradução de Bento Prado Jr. E Alberto Alonso Muñoz. - São Paulo: Editora 34, 2010.

DELEUZE, G.; GUATTARI, F. Mil Patlôs: capitalismo e esquizofrenia. Tradução de Ana Lúcia de Oliveira, Aurélio Guerra Neto e Célia Pinto Costa. Vol. 1. $2^{a}$ Edição. São Paulo: Ed. 34, 2011.

DELEUZE, G.; GUATTARI, F. Mil Patlôs: capitalismo e esquizofrenia. Tradução de Sueli Rolnik. Vol. 4. 2a Edição. São Paulo: Ed. 34, 2012.

KOHAN, W. O. Infância, estrangeiridade e ignorância. Ensaios de filosofia e educação. Belo Horizonte: Autêntica, 2007.

LEITE, C. D. P. Infância, experiência e tempo. São Paulo: Cultura Acadêmica, 2011.

\footnotetext{
' Bacharel e licenciada em Artes Visuais pela Universidade Federal de Santa Maria, Especialista em Metodologia do Ensino de Artes pelo Centro Universitário Internacional (UNINTER) e Mestra/Doutora em Educação na Linha de Pesquisa Educação e Artes pelo Programa de Pós-Graduação em Educação PPGE/UFSM na Universidade Federal de Santa Maria, RS. Professora pesquisadora do GEPAEC: Grupo de Estudos e Pesquisas em Arte, Educação e Cultura, diretório CNPq. Desenvolve pesquisa na área de Educação e Artes Visuais, com ênfase em Educação, nas temáticas: diários visuais, memória e infância. Trabalha com questões sobre animação e imagens com foco na fabulação. Atualmente professora dos Anos Iniciais na disciplina de Artes da Rede Marista - Santa Maria/RS.
}

Como citar esse artigo:

BARIN, Ana Cláudia. Animação, infância e fabulação: movimentos com o conceito devircriança e produção de arte no ensino remoto. Revista Digital do LAV, Santa Maria: UFSM, v. 14 , n. 2, p. 311-320, mai./ago. 2021. 